\title{
Pressure-Viscosity Response in the Inlet Zone for Quantitative Elastohydrodynamics
}

\author{
Revised January, 2016 \\ Scott Bair \\ Regents' Researcher \\ Georgia Institute of Technology, Center for High-Pressure Rheology \\ George W. Woodruff School of Mechanical Engineering \\ Atlanta, GA 30332-0405, USA \\ scott.bair@me.gatech.edu
}

\begin{abstract}
The descriptions employed in classical elastohydrodynamic lubrication (EHL) of the piezoviscous effect at low pressures characteristic of the inlet zone are simply inaccurate for low viscosity liquids. This article offers the 1952 McEwen equation for accurately describing the pressure-viscosity effect at low inlet pressures for those liquids with sufficiently high inflection pressure that the faster-than-exponential response does not significantly affect the viscosity in the inlet. The parameters of this model have significance for the classical EHL film thickness formulas and these parameters are listed for several low viscosity liquids including a refrigerant.
\end{abstract}

Key Words: elastohydrodynamic; film thickness; rheology; pressure-viscosity coefficient 


\section{INTRODUCTION}

In a letter to the editor of a tribology journal [1] seven coauthors suggested six years ago that the field of elastohydrodynamic lubrication (EHL or EHD) undertake a change in philosophy. At that time, the value of the viscosity employed for the analysis of EHL was considered a matter of personal choice, which was not to be influenced by accurate measurements in a viscometer. Indeed, the use of the exponential pressure-viscosity relation or the Roelands pressure-viscosity relation may indicate that the analysis was not based upon a realistic description of the pressure dependence [2]. There are numerous examples of comparisons of viscometer measurements with the viscosity used in classical EHL analysis [3-7] which emphasize these discrepancies.

Beginning with the first full EHL simulation employing real pressure and shear dependent viscosity, measured in viscometers [8], there have been revolutionary advances in the understanding of friction and film-forming. See [9-12] for examples. While it is apparent that the Newtonian film thickness solution is much less widely applicable than previously thought, Newtonian inlets do exist in practical problems and, even when the viscosity is shear dependent

in the inlet, it remains necessary to describe the pressure dependence of the low-shear viscosity to apply any shear-thinning solution using superposition.

In spite of the recent progress, there seems to be poor understanding in general of the pressure-viscosity response in the inlet zone as evidenced by the continuing use of inaccurate descriptions of the pressure-viscosity effect in a text on the subject [13] and a recent article [14]. This article offers a framework for accurately describing the piezoviscous effect at low inlet pressures for those liquids with sufficiently high inflection pressure that the faster-thanexponential response does not significantly affect the viscosity in the inlet. These liquids encompass most low viscosity liquid lubricants with the exception of traction fluids.

\section{PRESSURE-VISCOSITY RESPONSE IN THE INLET ZONE FOR CLASSICAL EHL}

The pressure in the inlet zone is generally regarded as being much less than the average or maximum Hertz pressure, although the assumed pressure at the nip varies widely from $70 \mathrm{MPa}$ 
[15] to 0.3 times the maximum Hertz pressure [16]. Blok [17] noted that the film must become almost parallel where the pressure, $p$, exceeds a value of about $3 p_{i a}$, where the asymptotic isoviscous pressure is

$$
p_{i a}=\int_{0}^{\infty} \frac{\mu(p=0) d p}{\mu(p)} .
$$

If the response were to be exponential (Arrhenius) with

$$
\mu=\mu_{0} \exp (\alpha p)
$$

then for Blok's criteria the inlet pressure reaches to $3 / \alpha$.

The exponential law (2), which applies near the pressure versus log viscosity inflection, has seen wide use in classical EHL. It has been widely and mistakenly attributed to a paper on effective viscosity of flowing solid glue by Barus [18], most known for describing extrudate swell, the "Barus effect". The origin of the exponential law is not clear. It is not likely to have originated from a researcher familiar with accurate measurements. Unfortunately, except for high viscosity oils at low temperature or for some traction fluids and ionic liquids, it is not a good approximation to real lubricant behavior at low pressure.

Most classical EHL articles which include a section on piezoviscous response describe the dependence of viscosity on low pressures with a narrative similar to this quotation from reference [14]. "At the relatively low pressures present in EHD contacts inlets (up to $150 \mathrm{MPa}$ ), $\alpha$ is often constant with pressure, so simple integration yields the Barus equation: $\mu(p)=\mu_{0} e^{\alpha p}$.” To show the inaccuracy of such a statement for modern oils, consider the viscosities measured by Lowitz and coworkers [19] in 1959 for 9-n-octylheptadecane (trioctylmethane or TOM) a prototype polyalphaolefin (PAO), shown in Figure 1. The exponential relation has been fitted to pressure intervals of 0 to 40, 60 to 100 and 140 to 180 MPa giving values of $\alpha$ of 12, 9.5 and 7.8 $\mathrm{GPa}^{-1}$, respectively. Similar data for this liquid, in good agreement, may be found in the 1953 ASME pressure-viscosity report [20]. Clearly, $\alpha$ is not constant in the interval 0 to $150 \mathrm{MPa}$.

The actual pressure interval over which the exponential rule applies may be shown in Figure 2 to be in the region of the pressure versus log viscosity inflection, where 
$d^{2} \ln \mu / d p^{2}=0$. The liquid is a PAO-6 (6 centistokes at $\left.100^{\circ} \mathrm{C}\right)$. The exponential relation has been fitted to pressure intervals of 0 to 70, 70 to 150 and 700 to $1100 \mathrm{MPa}$ giving values of $\alpha$ of 18.5, 13.9 and $7.6 \mathrm{GPa}^{-1}$, respectively. Clearly, $\alpha$, should only be regarded as constant in the vicinity of the inflection situated at $p \approx 865 \mathrm{MPa}$.

The pressure-viscosity relation of Roelands [21] is in classical EHL often extolled as the preferred correlation (for example [22]) for the full range of EHL pressures.

$$
\mu=\mu_{p}\left(\frac{\mu_{0}}{\mu_{p}}\right)^{\left(\frac{p_{P}-p}{p_{P}}\right)^{Z}}
$$

This equation was derived from the concept of a pressure-viscosity pole at which all isotherms converge in the negative pressure (tensile) domain. Roelands suggested setting the pole parameters to universal values of $\mu_{p}=6.31 \times 10^{-5} \mathrm{~Pa} \cdot \mathrm{s}$ and $p_{p}=-0.196 \mathrm{GPa}$. He also set, as the upper limit of applicability, the inflection pressure, which he placed at 300-500 MPa [21]. Roelands [21] also warned that at low pressures, equation (3) understates the pressure dependence near ambient pressure. This is illustrated by the data in Figures 3 through 5 where equation (3) has been fitted to the data by minimizing the absolute average deviation. The liquids shown in Figures 3 through 5 are 9-n-octylheptadecane (TOM), a PAO-2 (Mobil SpectraSyn 2) and a jet engine oil meeting military specification L7808 grade 4, respectively.

There are conditions for which the Roelands model (3) fits data to experimental accuracy, for example, trimethylolpropane trioleate at $100^{\circ} \mathrm{C}$ and pressure to $1.3 \mathrm{GPa}$ [23]. However, a measurement in a viscometer is necessary to determine whether this model is appropriate and then viscosity measurements are essential to determine the parameters.

\section{PRESSURE-VISCOSITY RESPONSE IN THE INLET ZONE FOR QUANTITATIVE EHL}

With so many possible shortcomings, it is surprising that the Roelands model has been and remains the most common pressure-viscosity law in classical EHL. It seems to have been chosen for numerical stability [24] rather than accuracy. This model has not found use outside of tribology. In the field of thermophysical properties, where there is interest in accurate 
expressions for the pressure-viscosity effect and the bias of classical EHL [6] is absent, two correlations are the most widely used.

\subsection{The McEwen Model for EHL}

One is a simple polynomial in pressure, $\mu=\exp \left(a_{0}+a_{1} p+a_{2} p^{2}+a_{3} p^{3} \ldots\right)$, [25] for example. The other is the Tait-like equation [26].

$$
\mu=A \exp \left[B \ln \left(\frac{C+p}{C+p_{R}}\right)\right]
$$

If the reference pressure, $p_{R}$, is zero, or small enough to neglect (as for ambient pressure), this expression is equivalent to the 1952 McEwen model [27].

$$
\mu=\mu_{0}\left(1+\frac{\alpha^{*}}{q-1} p\right)^{q}, \quad q>1
$$

For convenient application in EHL, it is written here in terms of the reciprocal asymptotic isoviscous pressure coefficient, $\alpha^{*}=1 / p_{i a}$.

This equation was used in lubrication and subsequently abandoned. Many researchers in lubrication have attributed this model to a later 1962 article by Chu and Cameron [28] which appeared in the same journal. This model reappeared in tribology once in 1987 [29].

It may be noticed that this expression is equivalent to the Munro, Block and Piermarini [30] model for pressure greater than the inflection pressure with $Q=-q$.

$$
\mu=\mu_{0}\left(\frac{p_{\infty}}{p_{\infty}-p}\right)^{Q}
$$

Here, the viscosity is unbounded at $p=p_{\infty}=(1-q) / \alpha^{*}$ and since $\alpha^{*}$ and $p_{\infty}$ are both greater than zero, $q<1$. This model has not found widespread use since its pressure-Stickel function is 
not typical [31]. As discussed later, the pressure-Stickel function for glass-formers plots as a straight, descending line.

\subsection{Pressure-viscosity coefficients derived from the McEwen Model}

The structure of the McEwen model (5) allows for the ready calculation of two more of the several definitions of pressure-viscosity coefficient. The conventional pressure-viscosity coefficient [32] is

$$
\alpha_{0}=\left[\frac{d \ln \mu}{d p}\right]_{p=0}=\frac{\alpha^{*}}{\left(1-\frac{1}{q}\right)}, \quad q>1
$$

Another definition of pressure-viscosity coefficient was developed [33] to provide a parameter, $\alpha_{\text {film }}$, that quantifies the piezoviscous strength in such a way that the central film thickness would be equal for all Newtonian liquids with the same compressibility at the same contact conditions for liquids with the same values of $\alpha_{\text {film }}$ and $\mu_{0}$, respectively. The isoviscous pressure is

$$
p_{i}(p)=\int_{0}^{p} \frac{\mu(p=0) d \hat{p}}{\mu(\hat{p})}
$$

The pressure-viscosity coefficient for film thickness with general pressure-viscosity behavior [33] is

$$
\alpha_{f i l m}=\frac{1-\exp (-3)}{p_{i}\left(3 / \alpha^{*}\right)}
$$

when Blok's integral in equation (1) converges. In terms of the McEwen parameters it is

$$
\alpha_{f i l m}=\frac{\alpha^{*}(1-\exp (-3))}{1-\left[1+\frac{3}{q-1}\right]^{1-q}}
$$


The McEwen model has been fitted to the data in Figures 3 through 5 and the parameters are listed in Table 1 along with the three pressure-viscosity coefficients. The improved fit of this model over the Roelands equation (3) should be clear from the figures. In the case of TOM, the average absolute deviation was $0.6 \%$ for McEwen and $4.5 \%$ for Roelands.

\subsection{Limitations of the McEwen Model}

The viscosity of a reference liquid, squalane, has been extensively measured to high pressure in various laboratories [34-37]. A correlation using the McEwen model in reference [34] yielded parameters at $65^{\circ} \mathrm{C}$ of $\mu_{0}=6.82 \mathrm{mPa} \cdot \mathrm{s}, q=6.88$ and $\alpha^{*}=14.77 \mathrm{GPa}^{-1}$. The deviations of this correlation from data of three publications [35-37] are plotted in Figure 6, showing systematic departures as pressure increases above about $325 \mathrm{MPa}$. This deviation results from the pressure-viscosity inflection discussed above.

The pressure-viscosity response may be correlated across the inflection with a hybrid of the McEwen and Paluch equations [38].

$$
\mu=\mu_{0}\left(1+\frac{\alpha^{*}}{q-1} p\right)^{q} \exp \left(\frac{C_{F} p}{p_{\infty}-p}\right)
$$

However, the meanings of the pressure-viscosity coefficients are then lost unless the inflection pressure is many times greater than $3 / \alpha^{*}$. For example, applying the hybrid equation (11) to data for squalane at $65^{\circ} \mathrm{C}$ to $1.2 \mathrm{GPa}$ gives $\alpha^{*}=11.59 \mathrm{GPa}^{-1}$ versus $14.77 \mathrm{GPa}^{-1}$ for equation (5). The inflection pressure for squalane at $65^{\circ} \mathrm{C}$ is about $1100 \mathrm{MPa}$ and $3 / \alpha^{*} \approx 200 \mathrm{MPa}$.

There exists a powerful method to test temperature-viscosity correlations and pressureviscosity correlations at high pressures. The Stickel analysis plots the Stickel function, $S(X)=[d \ln (\mu) / d X]^{-1 / 2}$ versus $X$, where $X=1 / T$ [39] or $X=p$ [31]. The Vogel, Tammann and Fulcher temperature-viscosity equation [40] plots $S(1 / T)$ versus $1 / T$ as a descending straight line and the Johari and Whalley [41] pressure-viscosity equation plots $S(p)$ versus $p$ also as a descending straight line. 
A modified Stickel function was recently introduced [38] as a test for the McEwen equation (5).

$$
S *(p)=[d \ln (\mu) / d p]^{-1}
$$

The McEwen equation plots $S^{*}(p)$ versus $p$ as an ascending straight line. This has been done for 9-n-Octylheptadecane in Figure 7 at 38 and $115^{\circ} \mathrm{C}$ indicating the appropriate behavior to $p=300 \mathrm{MPa}$. The PAO-6 is shown to depart from a straight line for pressure above about 400 $\mathrm{MPa}$ at $57^{\circ} \mathrm{C}$ in Figure 8. Here the McEwen model was fitted to PAO-6 for pressure up to 450 MPa.

Concentrated contacts within refrigeration compressors are lubricated by the process liquid which contains refrigerant [42]. The film thickness generated in these contacts must be influenced by the pressure-viscosity response of the refrigerant and such data are scarce. The viscosities reported in reference [43] were used to plot the modified Stickel function for the refrigerant, R134a, in Figure 8 and the parameters are listed in Table 1 . The response at $40^{\circ} \mathrm{C}$ is shown to be appropriate for the McEwen model. For higher temperatures, there is another type of inflection in the pressure-viscosity response where $d^{2} \mu / d p^{2}=0$ at experimental pressure. The McEwen model cannot capture this behavior and thermodynamic scaling is more appropriate here [43].

\section{CONCLUSION}

The analysis of film-forming in classical EHL has been hindered by an inaccurate description of the piezoviscous response at the low pressures representative of the inlet zone. Newtonian inlets do exist in practical problems and, even when the viscosity is shear dependent in the inlet, it remains necessary to describe the pressure dependence of the low-shear viscosity to apply any shear-thinning solution using superposition. The 1952 McEwen equation accurately describes the pressure-viscosity effect at low inlet pressures for low viscosity liquids. The parameters of this model have significance for the classical EHL film thickness formulas and these parameters are listed for several low viscosity liquids including a refrigerant. 


\section{Acknowledgements}

This work was supported by the Center for Compact and Efficient Fluid Power, a National Science Foundation Engineering Research Center funded under cooperative agreement number EEC-0540834. 


\section{NOMENCLATURE}

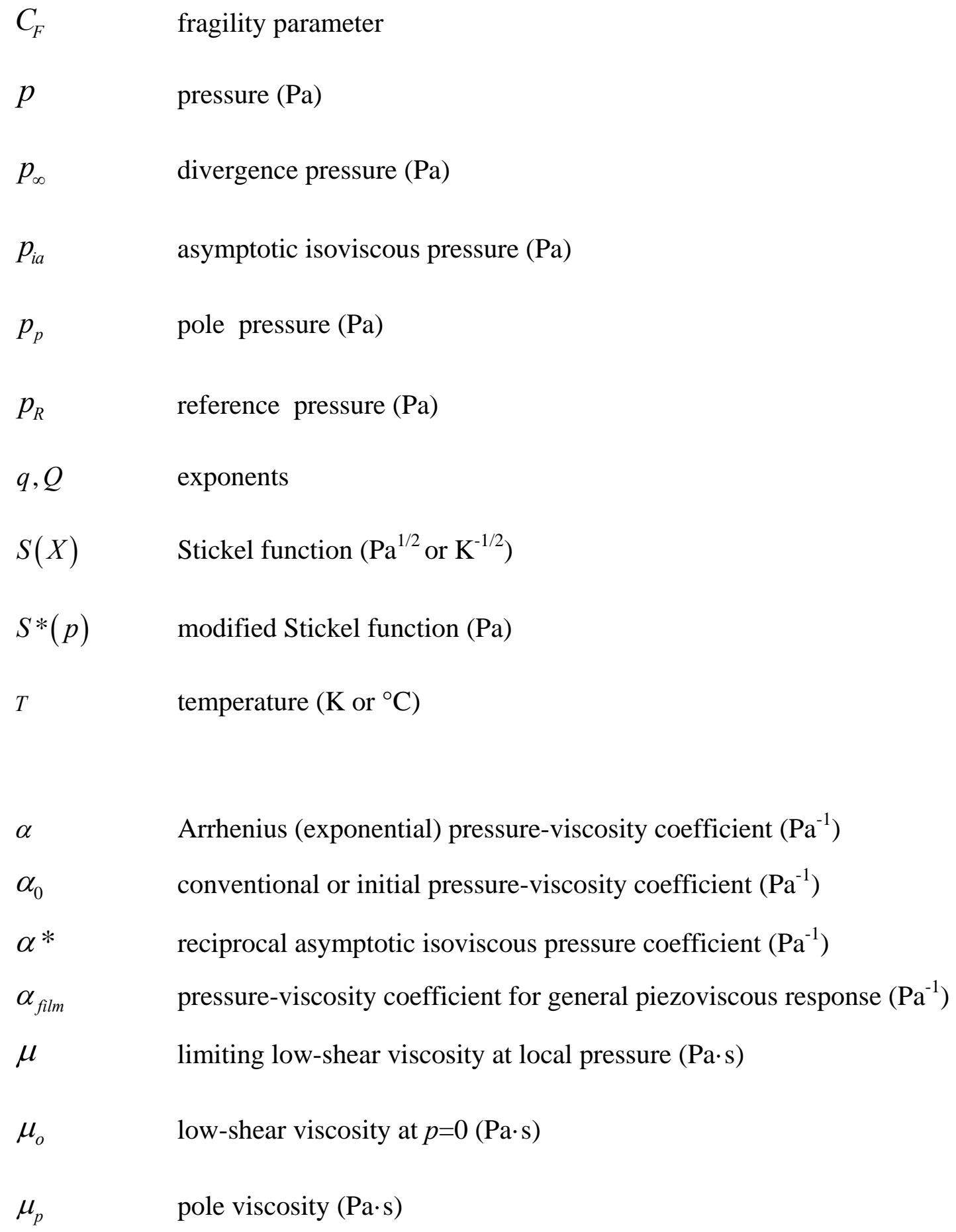




\section{References}

1. Bair, S., Fernandez, J., Khonsari, M. M., Krupka, I., Qureshi, F., Vergne, P., \& Wang, Q. J. (2009). Letter to the Editor. Proceedings of the Institution of Mechanical Engineers, Part J: Journal of Engineering Tribology, 223(4), i-ii.

2. Bair, S. (2004). Roelands' missing data. Proceedings of the Institution of Mechanical Engineers, Part J: Journal of Engineering Tribology, 218(1), 57-60.

3. Hutton, J. F., \& Phillips, M. C. (1973). High pressure viscosity of a polyphenyl ether measured with a new Couette viscometer. Nature, 245(140), 15-16.

4. Bair, S., \& Winer, W. O. (2000). The pressure-viscosity coefficient at Hertz pressure and its relation to concentrated contact traction. In Proceedings of the 26th Leeds-Lyon Symposium on Tribology 1999, Elsevier, Amsterdam, Tribology Series, 38, 433-443.

5. Bair, S., \& Casalini, R. (2008). A scaling parameter and function for the accurate correlation of viscosity with temperature and pressure across eight orders of magnitude of viscosity. Journal of Tribology, 130(4), 041802.

6. Bair, S. (2012). A critical assessment of the role of viscometers in quantitative elastohydrodynamics. Tribology Transactions, 55(3), 394-399.

7. Bair, S., Vergne, P., Kumar, P., Poll, G., Krupka, I., Hartl, M., ... \& Larsson, R. (2015). Comment on "History, Origins and Prediction of Elastohydrodynamic Friction" by Spikes and Jie. Tribology Letters, 58(1), 1-8.

8. Liu, Y., Wang, Q. J., Bair, S., \& Vergne, P. (2007). A quantitative solution for the full shearthinning EHL point contact problem including traction. Tribology Letters, 28(2), 171-181.

9. Kumar, P., Anuradha, P., \& Khonsari, M. M. (2010). Some important aspects of thermal elastohydrodynamic lubrication. Proceedings of the Institution of Mechanical Engineers, Part C: Journal of Mechanical Engineering Science, 224(12), 2588-2598.

10. Habchi, W., Bair, S., \& Vergne, P. (2013). On friction regimes in quantitative elastohydrodynamics. Tribology International, 58, 107-117.

11. Habchi, W., Bair, S., Qureshi, F., \& Covitch, M. (2013). A film thickness correction formula for double-Newtonian shear-thinning in rolling EHL circular contacts. Tribology Letters, 50(1), 59-66.

12. Bair, S., Krupka, I., Sperka, P., \& Hartl, M. (2013). Quantitative elastohydrodynamic film thickness of mechanically degraded oil. Tribology International, 64, 33-38. 
13. Schmid, S. R., Hamrock, B. J., \& Jacobson, B. O. (2014). Fundamentals of Machine Elements: SI Version. CRC Press.

14. Spikes, H. (2015). Basics of EHL for practical application. Lubrication Science, 27(1), 4567.

15. Jones Jr, W. R., Johnson, R. L., Winer, W. O., \& Sanborn, D. M. (1975). Pressure-viscosity measurements for several lubricants to $5.5 \times 10^{8}$ Newtons per square meter $\left(8 \times 10^{4} \mathrm{psi}\right)$ and $149^{\circ} \mathrm{C}$ (300F). ASLE TRANSACTIONS, 18(4), 249-262.

16. Greenwood, J. A., \& Kauzlarich, J. J. (1998). Elastohydrodynamic film thickness for shearthinning lubricants. Proceedings of the Institution of Mechanical Engineers, Part J: Journal of Engineering Tribology, 212(3), 179-191.

17. Blok H. (1963) Inverse problems in hydrodynamic lubrication and design directives for lubricated flexible surfaces. D. Muster, B. Sternlicht (Eds.), Proceedings International Symposium on Lubrication and Wear, Houston, TX, 1963, McCutchan, Berkeley (1965), pp. 779.

18. Barus, C, (1893) "Isothermals, Isopiestics and Isometrics Relative to Viscosity", American Journal of Science, Third Series, Vol. XLV, No.266, pp.87-96.

19. Lowitz, D. A., Spencer, J. W., Webb, W., \& Schiessler, R. W. (1959). Temperature-PressureStructure Effects on the Viscosity of Several Higher Hydrocarbons. The Journal of Chemical Physics, 30(1), 73-83.

20. Kleinschmidt, R.V., Bradbury, D. And Mark, M., Viscosity and Density of Over Forty Lubricating Fluids of Known Composition at Pressures to 150,000 psi and Temperatures to 425 $F$, ASME, New York, 1953.

21. Roelands, C. J. A. (1966). Correlational aspects of the viscosity-temperature-pressure relationship of lubricating oils (Doctoral dissertation, TU Delft, Delft University of Technology).

22. Höglund, E. (1999). Influence of lubricant properties on elastohydrodynamic lubrication. Wear, 232(2), 176-184.

23. Bair, S. S. (2007). High pressure rheology for quantitative elastohydrodynamics (Tribology Series Vol. 54). Elsevier, Amsterdam, p 113.

24. Yang, P., Kaneta, M., \& Masuda, S. (2005). Closure to "Discussion:'Quantitative Comparisons Between Measured and Solved EHL Dimples in Point Contacts,'(Yang, P., Kaneta, M., and Masuda, S., 2003, ASME J. of Tribology, 125 (1), pp. 210-214)”. Journal of Tribology, 127(2), 457-457. 
25. Harris, K. R. (2015). Temperature and Pressure Dependence of the Viscosities of Krytox GPL102 Oil and Di (pentaerythritol) Hexa (isononanoate). Journal of Chemical \& Engineering Data.

26. Comuñas, M. J. P., Baylaucq, A., Boned, C., \& Fernández, J. (2001). High-pressure measurements of the viscosity and density of two polyethers and two dialkyl carbonates. International journal of thermophysics, 22(3), 749-768.

27. McEwen, E. (1952) "The Effect of Variation of Viscosity with Pressure on the LoadCarrying capacity of the Oil Film between Gear-Teeth”, J. Inst. Petroleum, Vol.38, No.344-5, pp.646-672.

28. Chu, P. S. Y., \& Cameron, A. (1962). Pressure viscosity characteristics of lubricating oils. $J$. Inst. Petroleum, 48(5), 147-150.

29. Vergne, P., \& Berthe, D. (1987). Pressure viscosity and compressibility of different mineral oils. In Proc 13th Leeds-Lyon Symp Tribology (pp. 309-315).

30. Munro, R. G., Block, S., \& Piermarini, G. J. (1979). Correlation of the glass transition and the pressure dependence of viscosity in liquids. Journal of Applied Physics, 50(11), 6779-6783.

31. Casalini, R., \& Roland, C. M. (2004). Viscosity at the dynamic crossover in o-terphenyl and salol under high pressure. Physical review letters, 92(24), 245702.

32. Zhao, J., \& Sadeghi, F. (2003). Analysis of EHL circular contact shut down. Journal of tribology, 125(1), 76-90.

33. Bair, S., Liu, Y., \& Wang, Q. J. (2006). The pressure-viscosity coefficient for Newtonian EHL film thickness with general piezoviscous response. Journal of tribology, 128(3), 624-631.

34. Schmidt, K. A., Pagnutti, D., Curran, M. D., Singh, A., Trusler, J. M., Maitland, G. C., \& McBride-Wright, M. (2014). New Experimental Data and Reference Models for the Viscosity and Density of Squalane. Journal of Chemical \& Engineering Data, 60(1), 137-150.

35. Bair, S. (2006). Reference liquids for quantitative elastohydrodynamics: selection and rheological characterization. Tribology Letters, 22(2), 197-206.

36. Harris, K. R. (2009). Temperature and pressure dependence of the viscosities of 2-ethylhexyl benzoate, bis (2-ethylhexyl) phthalate, 2, 6, 10, 15, 19, 23-hexamethyltetracosane (squalane), and diisodecyl phthalate†. Journal of Chemical \& Engineering Data, 54(9), 2729-2738.

37. Comuñas, M. J., Paredes, X., Gaciño, F. M., Fernández, J., Bazile, J. P., Boned, C., Daridon, J.L., Galliero, G., Pauly, J. \& Harris, K. R. (2014). Viscosity measurements for squalane at high pressures to 350MPa from $\mathrm{T}=(293.15$ to 363.15$) \mathrm{K}$. The Journal of Chemical Thermodynamics, 69, 201-208. 
38. Bair, S. (2006). Choosing Pressure-Viscosity Relations. High Temperatures--High Pressures, 44(6), 415-429.

39. Stickel, F., Fischer, E. W., \& Richert, R. (1996). Dynamics of glass-forming liquids. II. Detailed comparison of dielectric relaxation, dc-conductivity, and viscosity data. The Journal of chemical physics, 104(5), 2043-2055.

40. Angell, C. A. (1995). Formation of glasses from liquids and biopolymers. Science, 267(5206), 1924-1935.

41. Johari, G. P., \& Whalley, E. (1972). Dielectric properties of glycerol in the range 0.1-10 5 Hz, 218-357 K, 0-53 kb. In Faraday Symposia of the Chemical Society (Vol. 6, pp. 23-41). Royal Society of Chemistry.

42. Tuomas, R., \& Jonsson, U. (2000). Influence of refrigerant on viscosity and pressureviscosity coefficient of refrigeration compressor lubricants. in Thinning Films and Tribological Interface, Tribology Series, 38 (Elsevier Science B.V, Amsterdam) 419-423.

43. Laesecke, A., \& Bair, S. (2011). High-pressure viscosity measurements of 1, 1, 1, 2tetrafluoroethane. International Journal of Thermophysics, 32(5), 925-941. 
Table 1. Parameters of the McEwen model and derived pressure-viscosity coefficients

\begin{tabular}{|c|c|c|c|c|c|c|c|c|c|c|c|c|c|}
\hline Material: & TOM & TOM & TOM & TOM & TOM & PAO-2 & PAO-2 & L7808 & L7808 & PAO-6 & R134a & $\begin{array}{c}\text { 4cs } \\
\text { grp3 }\end{array}$ & $\begin{array}{c}\text { 4cs } \\
\text { grp3 }\end{array}$ \\
\hline $\begin{array}{l}\text { Temperature / } \\
{ }^{\circ} \mathrm{C} \text { : }\end{array}$ & 37.8 & 60.0 & 79.4 & 98.9 & 115 & 40 & 150 & 100 & 150 & 57 & 40 & 140 & 180 \\
\hline$\mu_{0} / \mathrm{mPa} \cdot \mathrm{s}$ & 7.08 & 3.92 & 2.61 & 1.874 & 1.483 & 3.78 & 0.662 & 3.67 & 1.708 & 20.06 & 0.1838 & 1.70 & 1.09 \\
\hline$\alpha^{*} / \mathrm{GPa}^{-1}$ & 12.17 & 10.76 & 9.84 & 8.81 & 8.30 & 12.38 & 6.52 & 9.57 & 7.83 & 16.7 & 2.81 & 9.33 & 7.96 \\
\hline$q$ & 5.59 & 4.45 & 4.11 & 3.58 & 3.21 & 4.43 & 1.94 & 4.01 & 3.33 & 5.47 & 1.293 & 3.25 & 2.605 \\
\hline$\alpha_{0} / \mathrm{GPa}^{-1}$ & 14.8 & 13.9 & 13.0 & 12.2 & 12.1 & 16.0 & 13.5 & 12.7 & 11.2 & 20.4 & 12.4 & 13.5 & 12.9 \\
\hline$\alpha_{\text {film }} / \mathrm{GPa}^{-1}$ & 12.8 & 11.6 & 10.7 & 9.7 & 9.3 & 13.3 & 8.4 & 10.4 & 8.7 & 17.6 & 5.3 & 10.4 & 9.3 \\
\hline
\end{tabular}




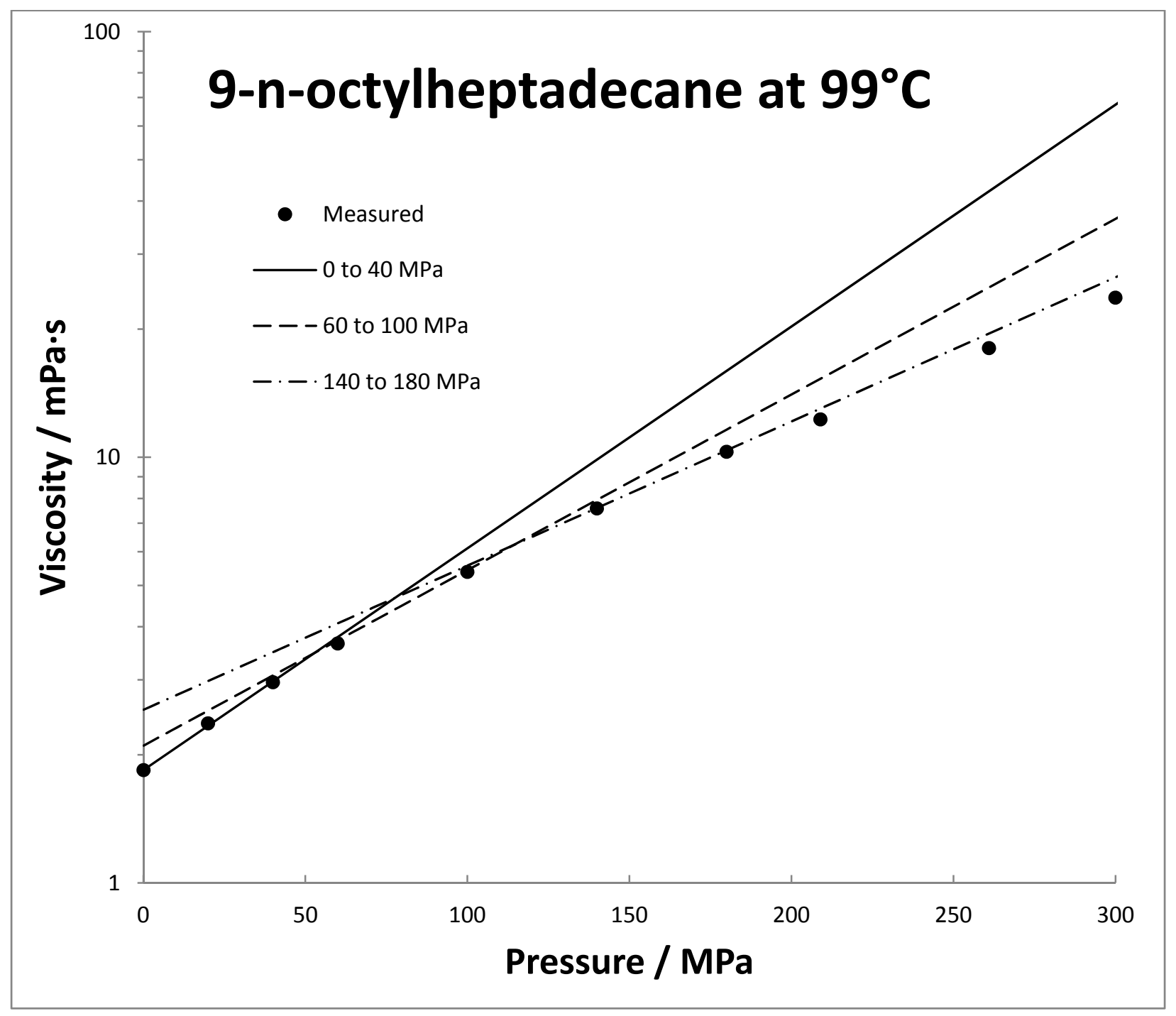

Figure 1. The viscosity of 9-n-Octylheptadecane from Lowitz, et al. [19]. The exponential relation has been fitted to pressure intervals giving values of $\alpha: 0$ to $40 \mathrm{MPa}, 12 \mathrm{GPa}^{-1} ; 60$ to $100 \mathrm{MPa}$, 9.5 $\mathrm{GPa}^{-1} ; 140$ to $180 \mathrm{MPa}, 7.8 \mathrm{GPa}^{-1}$. 


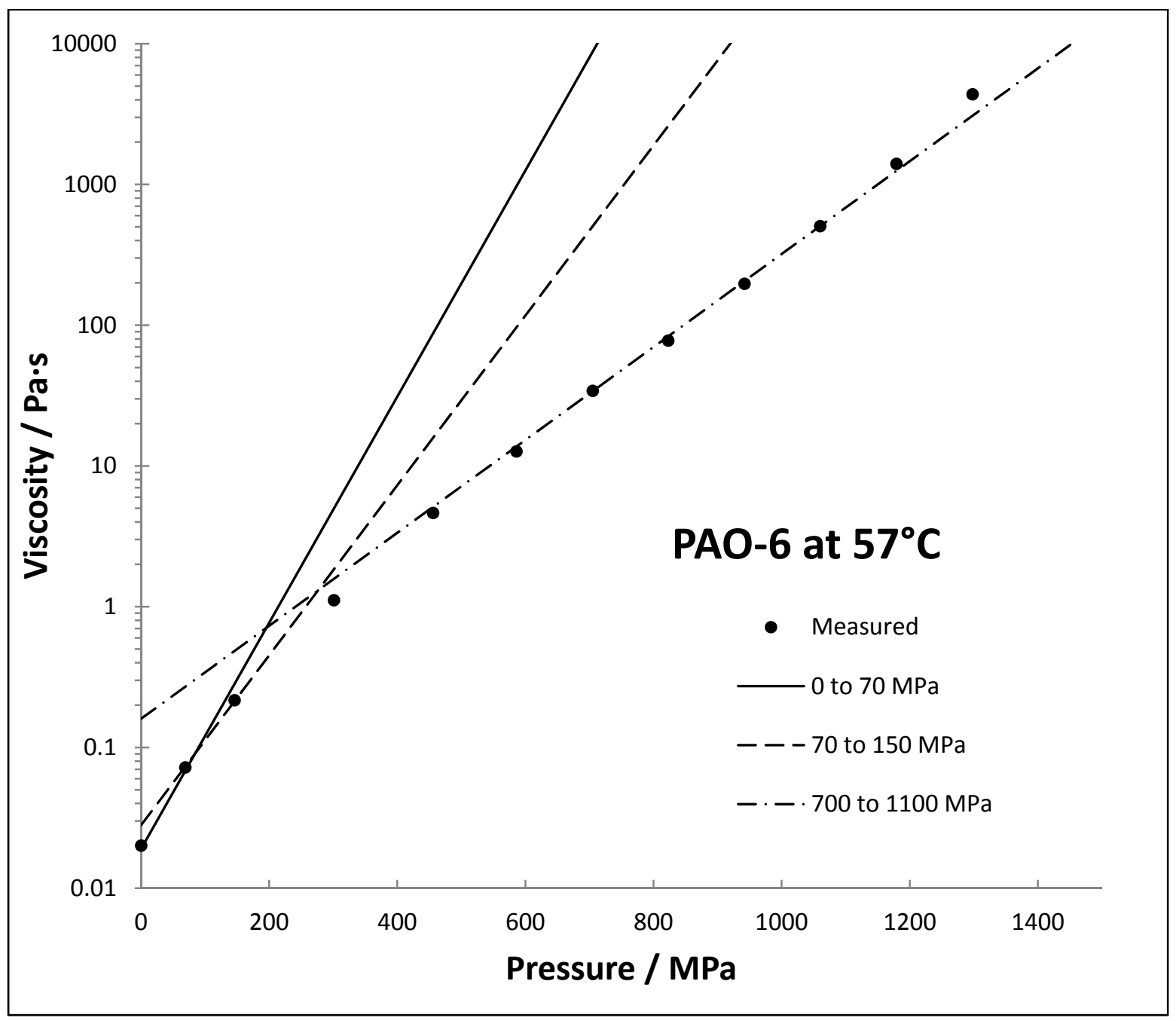

Figure 2. Viscosity of a PAO-6 measured in the author's laboratory. The exponential relation has been fitted to pressure intervals giving values of $\alpha: 0$ to $70 \mathrm{MPa}, 18.5 \mathrm{GPa}^{-1} ; 70$ to $150 \mathrm{MPa}$, $13.9 \mathrm{GPa}^{-1} ; 700$ to $1100 \mathrm{MPa}, 7.6 \mathrm{GPa}^{-1}$. 


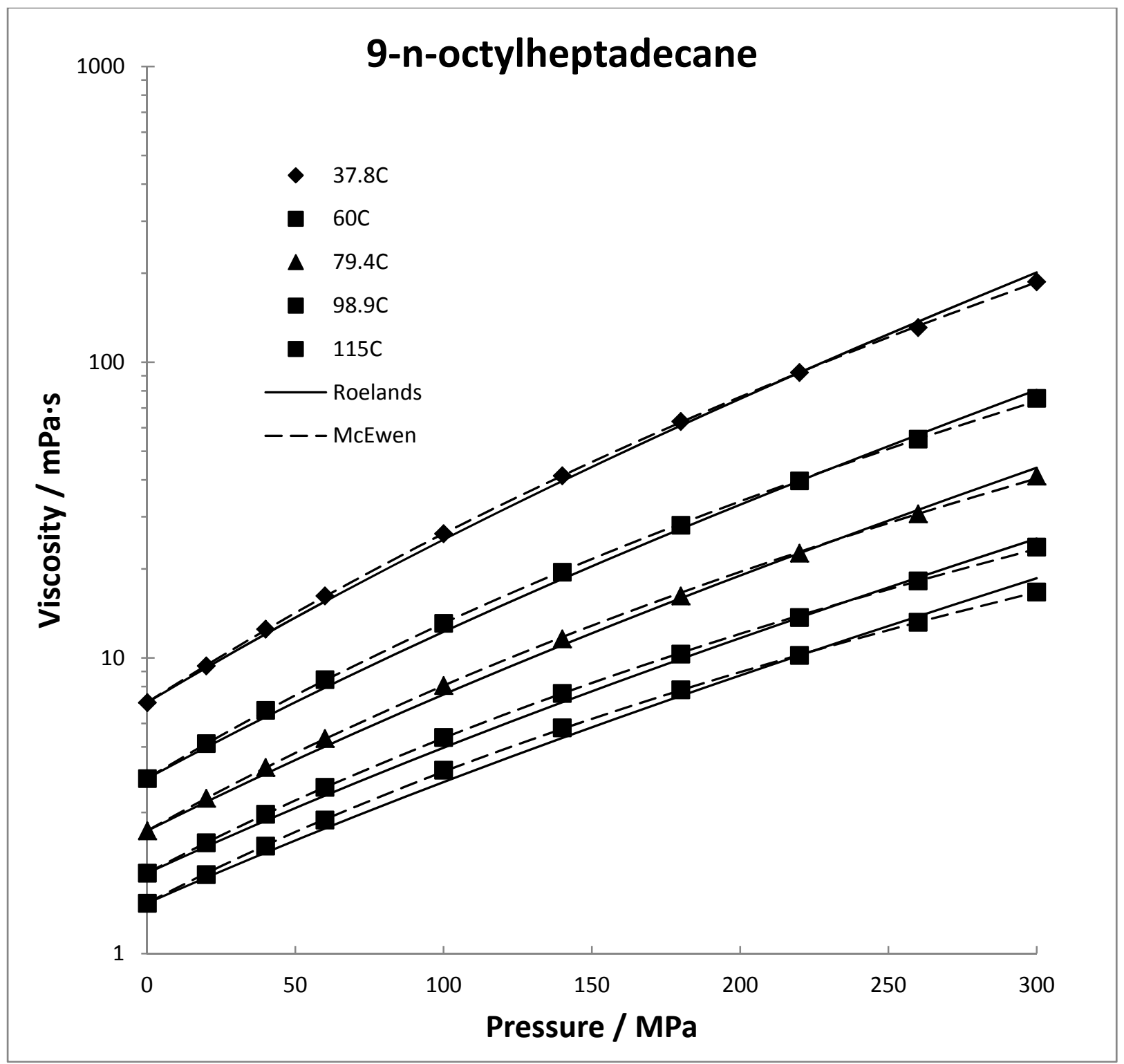

Figure 3. The viscosity of 9-n-Octylheptadecane from Lowitz, et al. [19] comparing Roelands with McEwen. 


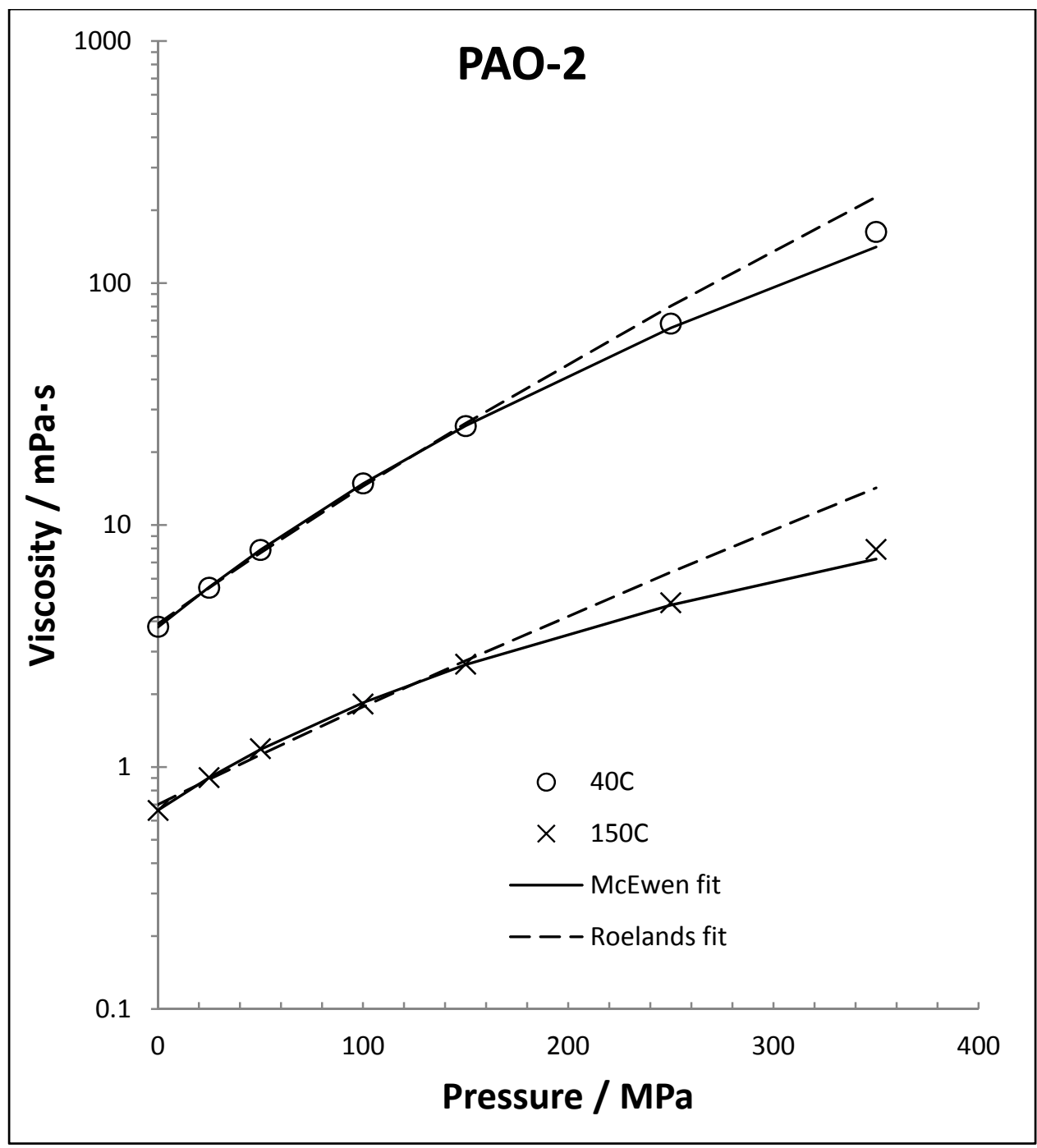

Figure 4. The viscosity of a PAO-2 (Mobil SpectraSyn 2) comparing Roelands with McEwen. 


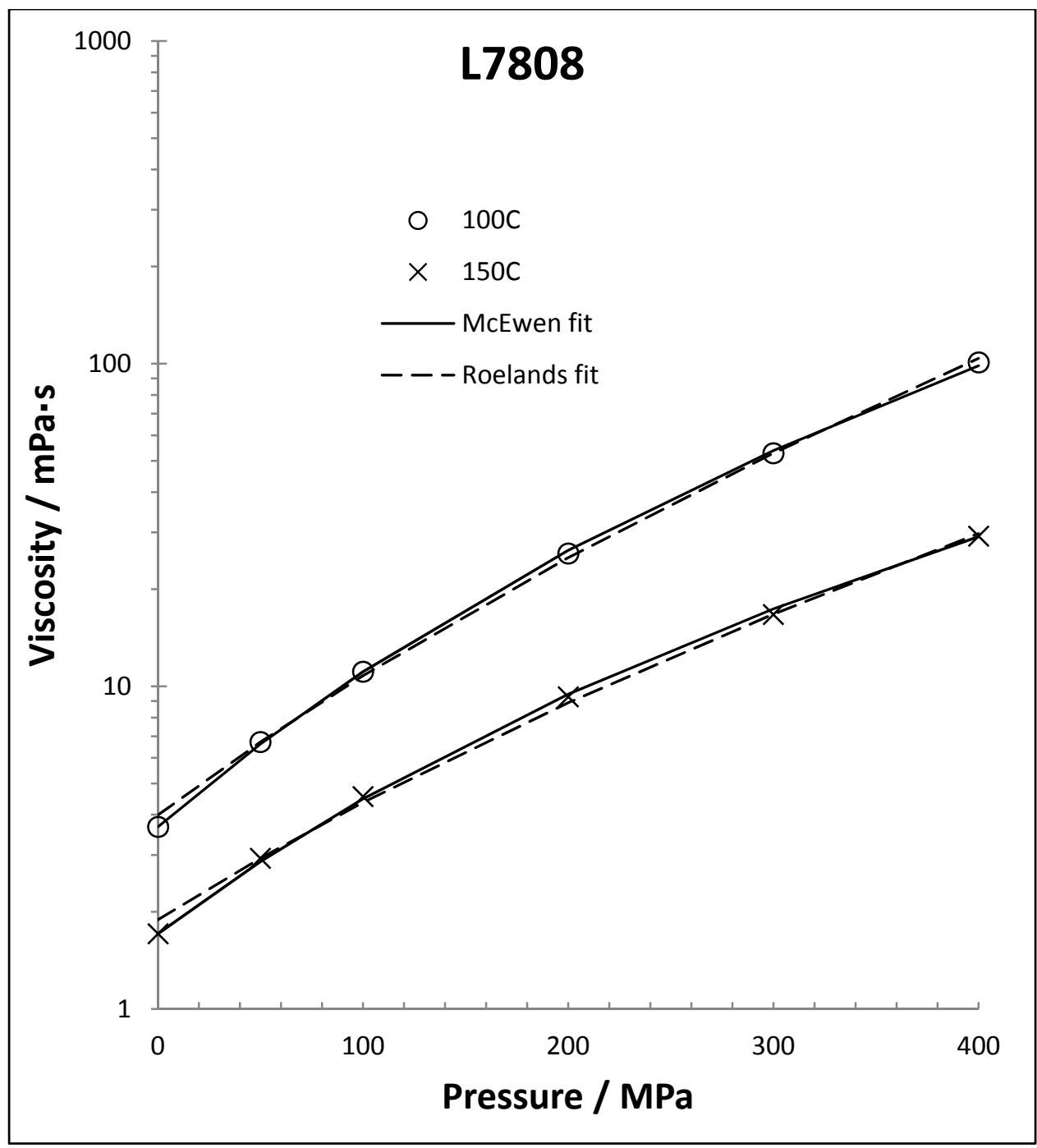

Figure 5. The viscosity of a jet engine oil meeting military specification L7808 grade 4, comparing Roelands with McEwen. 


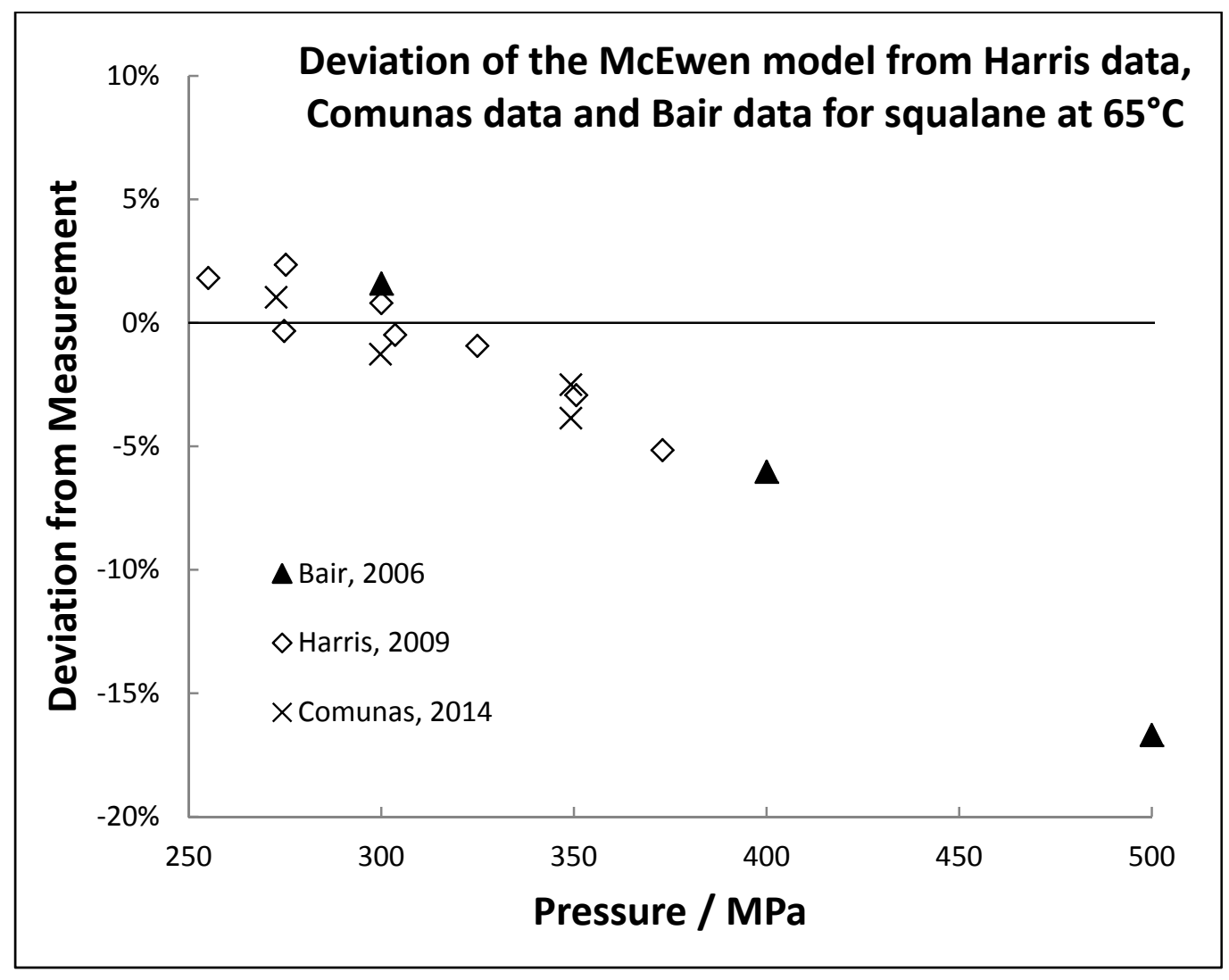

Figure 6. Deviation of the McEwen model for increasing pressure from data of three laboratories for squalane at $65^{\circ} \mathrm{C}$. 


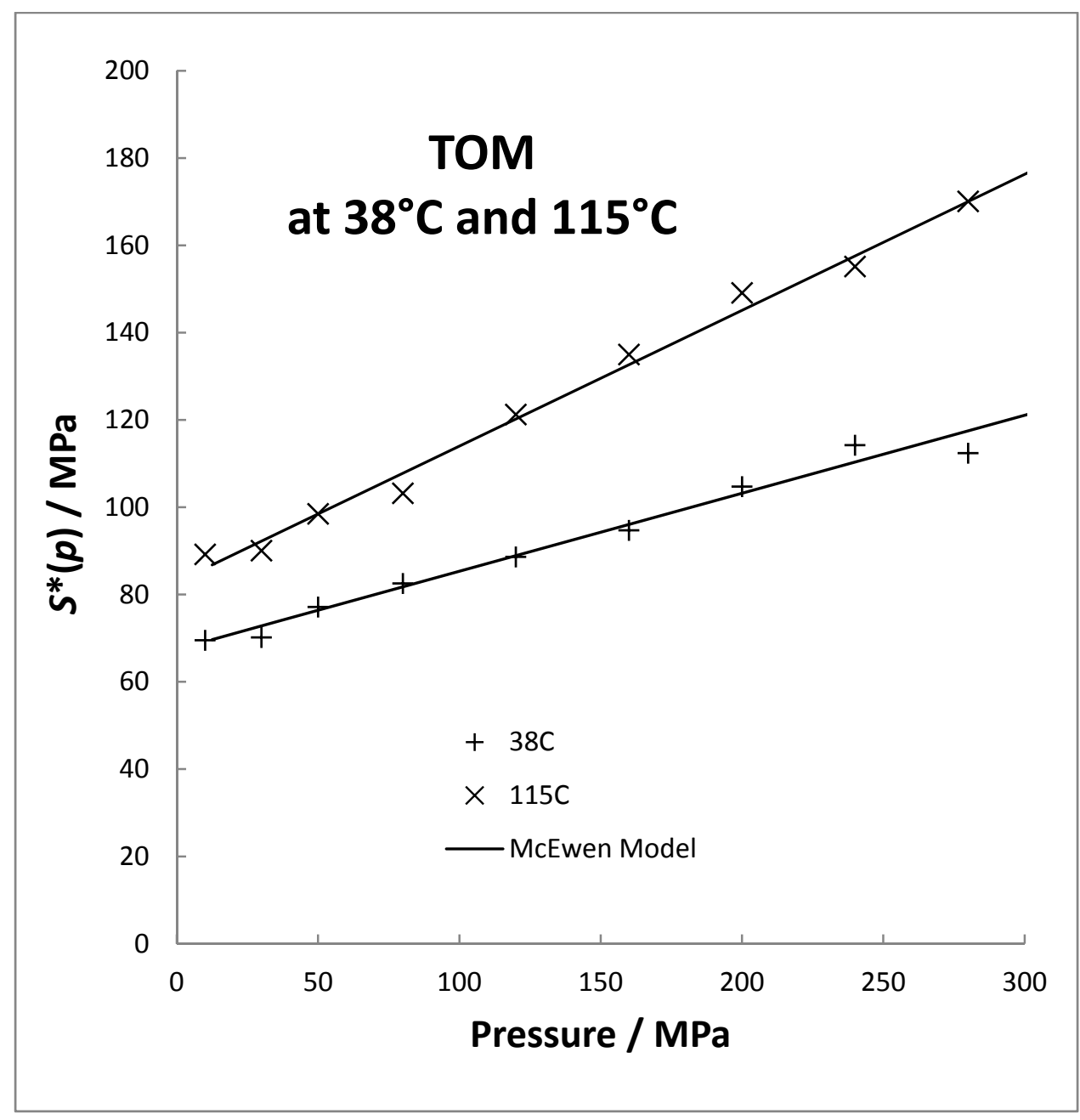

Figure 7. The modified Stickel function for 9-n-Octylheptadecane showing ascending straight line behavior. 


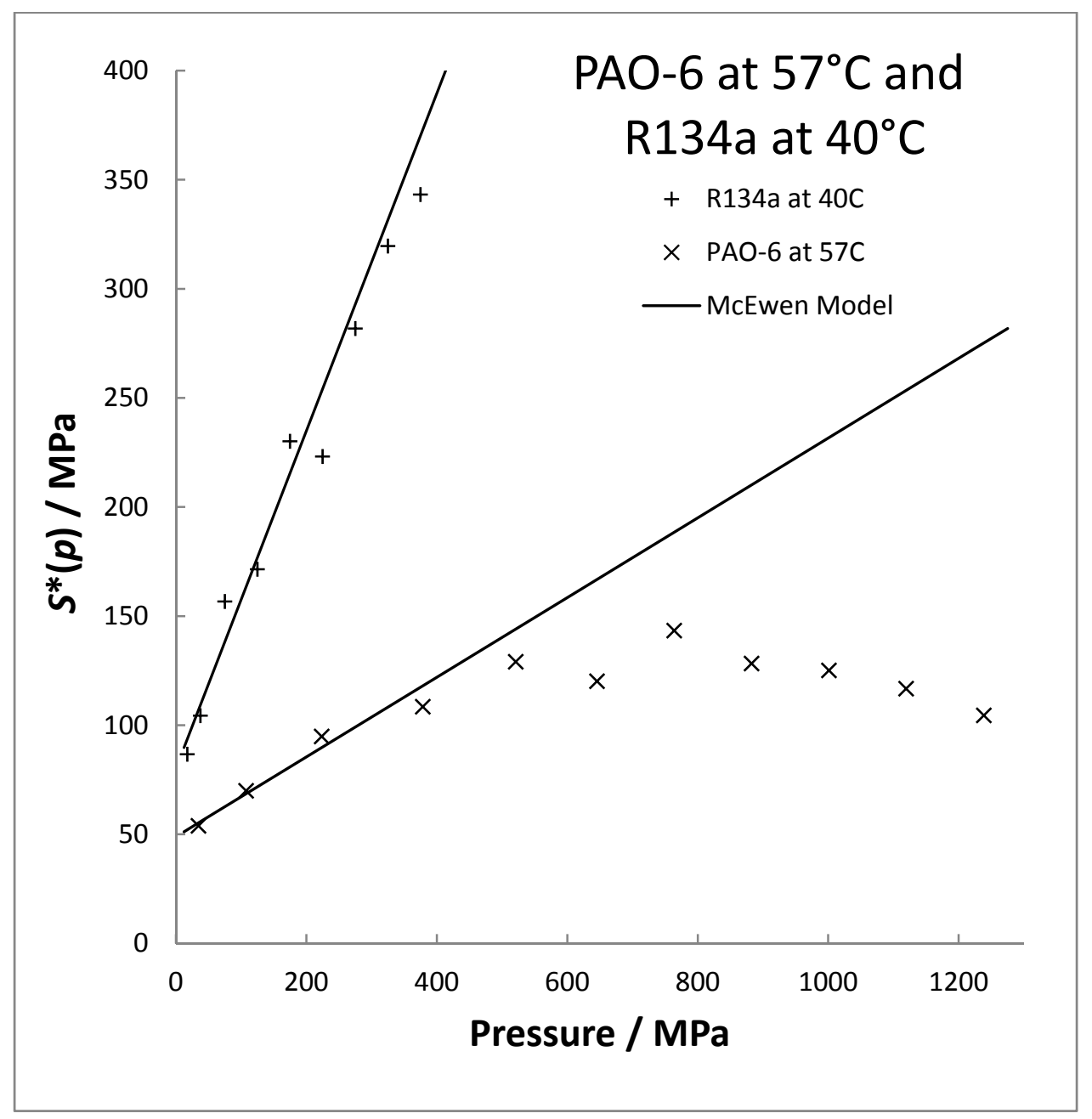

Figure 8. The modified Stickel function for the PAO-6 and a refrigerant, R134a. 